\title{
Controvérsias sobre o uso do DSM para diagnósticos de transtornos mentais
}

\author{
| ${ }^{1}$ Fernanda Martinhago, ${ }^{2}$ Sandra Caponi |
}

Resumo: O número de diagnósticos de transtornos mentais cresceu significativamente em paralelo à disseminação das edições do Manual Diagnóstico e Estatístico de Transtornos Mentais (DSM). Neste contexto, desenvolvemos este ensaio com a finalidade de compreender o uso do DSM como instrumento para fundamentar os diagnósticos de transtornos mentais. Para embasar o presente estudo, lançou-se mão de publicaçôes científicas de autores que discutiram as ediçóes do DSM, assim como as classificaçôes psiquiátricas. Constatamos que há controvérsias em relação ao Manual, as quais descrevemos por um lado como conveniências e, por outro, como críticas. Há lugares em que esta lógica do DSM é conveniente, uma vez que gera benefícios a diversos setores, como seguros de saúde e indústria farmacêutica. As principais críticas ao DSM ressaltam o fato de o Manual transformar o sofrimento psíquico em patologias de cunho cerebral.

> Palavras-chave: Manual Diagnóstico e Estatístico de Transtornos Mentais; classificação; diagnóstico; psiquiatria.
1 Programa de Pós-Graduação Interdisciplinar em Ciências Humanas, Universidade Federal de Santa Catarina. FlorianópolisSC, Brasil (martinhagofernanda@ gmail.com).

ORCID: 0000-0002-2929-7739.

${ }^{2}$ Sociologia, Universidade Federal de Santa Catarina. Florianópolis-SC, Brasil (sandracaponi@gmail.com). ORCID: 0000-0001-8180-944X.

Recebido em: 02/06/2018 Revisado em: 05/02/2019 Aprovado em: 15/02/2019 


\section{Introdução}

Nos últimos anos, a proliferação de diagnósticos de transtornos mentais tem tomado uma proporção devastadora, atingindo a população mundial. Isso seria um indicativo de que a população está realmente tomada por problemas de saúde mental? (WHITAKER, 2011).

O sofrimento psíquico é bastante complexo e exige um olhar clínico minucioso sobre o sujeito e o seu contexto, antes de ser estabelecido um diagnóstico de transtorno mental (MARTINHAGO, 2017). O número de pessoas diagnosticadas com patologias mentais aumentou significativamente em paralelo às ediçôes do Manual Diagnóstico e Estatístico de Transtornos Mentais, conhecido como DSM, devido ao título original em inglês Diagnostic and Statistical Manual of Mental Disorders. O Manual apresenta uma classificaçáo dos comportamentos ditos desviantes, a qual foi sendo ampliada no decorrer de cada edição, conforme podemos observar no decorrer da trajetória dos DSMs (FRANCES, 2016; CAPONI, 2014, 2012).

$\mathrm{Na}$ segunda metade do século XX, foi criada a necessidade de sistematizar os diagnósticos referentes às patologias mentais, de modo que houvesse um consenso terminológico entre os clínicos, ou seja, uma padronização nas categorias de doenças, as quais atenderiam às finalidades acadêmicas, terapêuticas, legais, administrativas e financeiras (ALARCÓN; FREEMAN, 2015).

Em 1952, a Associação Americana de Psiquiatria (APA), com intuito de suprir estas necessidades, publicou a primeira versão do DSM-I, com 106 categorias, pautado em um enfoque predominantemente psicanalítico. No ano de 1968, foi publicado o DSM-II, com 182 categorias, não apresentando alterações significativas em relação à primeira versão (ARAÚJO; LOTUFO NETO, 2014). No final da década de 1970, constataram-se divergências entre os diagnósticos psiquiátricos dos Estados Unidos e dos países europeus. Uma nova versão do Manual foi elaborada para aperfeiçoar a uniformidade e a validade do diagnóstico psiquiátrico, assim como padronizar as práticas de diagnóstico. Em 1980, o DSM-III foi publicado com 265 categorias, fundamentadas em critérios da medicina baseada em evidências (DUNKER, 2014). Esse fato foi considerado uma revolução científica. O DSM-III foi o marco da mudança de paradigma da psiquiatria, que até o momento era regida predominantemente pela psicanálise (MARTINHAGO; CAPONI, 2019). 
A quarta edição do Manual - DSM-IV - foi publicada em 1994, com 297 categorias; os diagnósticos psiquiátricos foram organizados em cinco eixos distribuídos em 886 páginas. Neste Manual, a principal mudança em relação às versôes anteriores foi a inclusão de um critério de significância clínica para praticamente metade das categorias que tinham sintomas e causavam sofrimento clinicamente importante ou prejuízo no funcionamento social ou ocupacional, entre outras áreas (DUNKER, 2014). A última edição do Manual - o DSM-V - foi publicada em maio de 2013, fundamentada no modelo categorial organizado em três sessôes, totalizando 947 páginas. A seção I apresenta as orientaçôes para o uso clínico e forense. A seção II descreve os critérios e códigos diagnósticos dos transtornos. E, por último, na seção III estão os instrumentos para as avaliaçôes dos sintomas, os critérios sobre a formulação cultural dos transtornos, o modelo alternativo para os transtornos de personalidade e uma descrição das condiçôes clínicas para estudos posteriores (APA, 2013).

Mediante a trajetória das edições dos DSMs, desenvolvemos este ensaio com a finalidade de compreender o uso do DSM como instrumento para fundamentar os diagnósticos de transtornos mentais. Para embasar este estudo, lançou-se mão de publicaçóes científicas - livros e artigos - de autores que discutiram as ediçóes do DSM, bem como as classificaçóes em psiquiatria de modo mais amplo. O presente ensaio resulta de uma parte da pesquisa realizada para a tese doutoral, desenvolvida de 2013 a 2017.

\section{Racionalidade diagnóstica do DSM}

A racionalidade diagnóstica do DSM coloca em xeque a psiquiatria e seus paradigmas. Neste sentido, expóem-se os argumentos de autores que apontam controvérsias tanto no âmbito da psiquiatria quanto no da racionalidade diagnóstica dos DSMs.

Segundo Berrios (2007, p.11), a psiquiatria é o "conjunto de narrativas desenvolvidas (principalmente por sociedades ocidentais) para configurar, explicar e lidar com fenômenos comportamentais, os quais, com base em critérios sociais, mais do que neurobiológicos, foram definidos como desvios”. Para Izaguirre (2011), a psiquiatria não é uma ciência e está distante de conquistar este objetivo. Ela estaria relacionada ao desenvolvimento de outras disciplinas heterogêneas entre si, nas quais busca se embasar. Todavia, estas lhe proporcionariam mais interrogações do que soluções. 
No decorrer da História, a psiquiatria estabelece três paradigmas: o primeiro é marcado pela "alienação mental" - fundamentada por Pinel e outros autores -, que permaneceu desde o final do século XVIII até a metade do século XIX (1793 a 1854). O segundo paradigma rompeu com a ideia de doença ou afecção única, onde os alienistas desenvolveram a descrição das doenças mentais e a organização dos quadros classificatórios. Nesse período, ocorreu a entrada da psiquiatria na medicina, momento em que se desenvolveram diversas classificaçóes, tendo como destaque as ediçôes da classificação de Kraepelin. E o terceiro é denominado de "estruturas psicopatológicas", devido à influência de diversas disciplinas dessa época (Gestalttheorie, neurobiologia, fenomenologia, os formalistas russos, o estudo dos mitos na antropologia do século XX, a semiologia e a linguística, as matemáticas e a psicanálise). O fundamental no terceiro paradigma foi o estabelecimento dos três grupos: neuroses, perversão e psicoses. Ao final do estabelecimento do terceiro paradigma, desenvolveram-se novos psicofármacos, o que, progressivamente, se tornou destaque e impulsionou os estudos sobre a neurociência e a genética, fato que talvez caracterize um novo paradigma da psiquiatria (IZAGUIRRE, 2011). Este autor questiona se realmente as neurociências, os psicofármacos e a genética poderão constituir o novo paradigma da psiquiatria.

A temática que envolve esta questão é discutida por Esperanza (2011), afirmando que a psiquiatria nunca encontrou um "substrato anátomoclínico" que tornasse possível incluí-la legitimamente no campo da medicina, embora ainda continue procurando. Para a autora, o DSM, bem como a CID, é produto condizente com o "vazio de saber" que se aloja no interior da psiquiatria e possibilita o seu traslado para a medicina geral ou para o "dinamismo médico-farmacêutico". Esperanza (2011, p. 54) acrescenta que:

[...] até hoje, não somente a psiquiatria não inventou nenhuma nova entidade, como tampouco pôde encontrar o correlato orgânico esperado. Nem sequer a teoria da neurotransmissão com sua açáo psicofarmacológica pode suturar esse passo que acossa a psiquiatria desde sempre, posto que segue se apresentando com um desejo assintótico: um correlato orgânico sempre possível, mas nunca demonstrado.

Nesta direção, ao falar sobre a sobrevalorização dos diagnósticos mediante a análise dos efeitos dos medicamentos, Dunker (2014, p. 94) afirma que "a unidade perdida com o sequestro da neurose, como hipótese que unifica história de vida, sintomas e personalidade, é reencontrada na unidade de um objeto: a medicação". 
O autor relembra que, no ano de 1958, surge a hipótese da recaptura da noradrelina para explicar o mecanismo da ansiedade. Da mesma forma, em 1960, houve a relação da dopamina com a esquizofrenia. Nos anos 1970, houve a associação entre a serotonina e a depressão e, na década de 1980, a relação da endorfina com os circuitos de prazer. Trata-se da mesma matriz hipotética que é reaplicada em diferentes casos, cujo transtorno é um déficit da substância neuronal, e a medicação age de modo compensatório, com a justificativa de que o corpo não está conseguindo produzir. Esta hipótese desconsidera que os estados mentais podem ser produzidos de forma inédita no sentido proprioceptivo, ou seja, de se perceber conforme as informaçóes que chegam ao cérebro e colaboram para a ação, de modo que temos consciência da posição, assim como na experiência corporal e significação do sujeito. Dunker (2014, p. 95) cita como exemplo o metilfenidato (Ritalina), cujo uso prolongado pode determinar "um 'antes' e um 'depois' da medicação, que estabelece uma nova unidade no eu, mas esta é criada pela medicação e não pressuposta por ela”.

Para Dunker (2014), as descobertas em torno dos neurotransmissores são questionáveis. Ao mesmo tempo, é também difícil compreender como:

Palavras, principalmente metáforas, narrativas ou experiências de linguagem em contexto intersubjetivo induzem à receptação e à distribuição de neurotransmissores como dopamina, serotonina, noradrenalina e endorfinas. Palavras mudam o seu cérebro, e o seu cérebro muda suas palavras, mas não da mesma maneira (DUNKER, 2014, p. 95).

A racionalidade diagnóstica do DSM, considerada hegemônica na contemporaneidade, "permite alienar o sujeito de e em sua própria forma de vida" (DUNKER, 2014, p. 96). O autor ainda questiona "qual seria sua implicação em um 'estado de adoecimento' contra o qual ele nada pode, pois afinal é seu cérebro que o domina?"

$\mathrm{Na}$ prática clínica, há muitas controvérsias com relação às classificações psiquiátricas, pois a psiquiatria rompe com as teorias de cunho crítico e filosófico que constituíam as características das patologias mentais. Tais influências filosóficas podem ser observadas em Pinel, que se baseia no pensamento de Hegel, no de Kraepelin (psiquiatria clássica alemã) pela teoria de Kant, em Esquirol e em Morel (psiquiatria clássica francesa), fundamentado no positivismo contemporâneo e na psiquiatria de Karl Jaspers influenciada por Husserl (BERRIOS, 1996). Posteriormente, em meados do século $\mathrm{XX}$, a psicanálise é incluída neste rol psiquiátrico-filosófico. Como ainda chama a atenção Dunker (2014, p.86): 


\begin{abstract}
Não que o programa contido no Manual Diagnóstico e Estatístico de Transtornos Mentais esteja isento de implicações filosóficas, éticas e epistemológicas, mas estas jamais são assumidas explicitamente, e o centro dessa problemática é deslocado para o campo genérico da fundamentação das ciências biológicas. $\mathrm{O}$ fato que nos interessa é o rompimento do nexo com os discursos psicanalítico e social que faziam a patologia mental depender dos modos de subjetivação e socialização em curso em um dado regime de racionalidade. Dessa maneira, é bastante plausível que tais modos de subjetivação e socialização encontrem-se ainda presentes nas categorias psiquiátricas, posto que sua formação histórica acusa esse regime de dependência. Ocorre que tal fato tornou-se invisível e apagado da prática diagnóstica corrente ou das razóes que a justificam.
\end{abstract}

De acordo com Dunker e Kyrillos Neto (2011), o DSM é um instrumento relevante para compreender a transformaçáo desse duplo sistema de correspondência psicanalítico-psiquiátrico e psicopatológico-filosófico. Em 1952, quando surgiu a primeira versão do DSM, houve o reconhecimento dos esforços da psicanálise que antecederam este manual. A história das relaçôes entre a psicanálise e a psiquiatria revela que talvez haja um comprometimento da psicanálise com a psiquiatria muito mais significativo do que a psicanálise atualmente gostaria de admitir e também uma dependência da psiquiatria em relação à psicanálise muito mais ampla do que a psiquiatria está disposta a reconhecer (Dunker; Kyrillos Neto, 2011). Foi a partir do DSM-III (1980-1987) que a psiquiatria deu uma grande virada, removendo as categorias e signos clínicos da psicanálise e passando a se considerar como ateórica, deslocando-se para o campo das ciências biológicas, e assim segue as sucessivas edições do Manual até o DSM-V, com fundamentação na psiquiatria baseada em evidências.

Para Maldonado et al. (2011), foi Kraepelin quem implantou um sistema de classificação baseado em marcos teóricos, observação e medição das psicopatologias. As categorias atualmente são oriundas das classificaçôes, cujas referências de maior uso no campo da saúde mental são o DSM, patrocinado pela APA, e a Classificação Internacional de Doenças (CID), apoiada pela Organização Mundial da Saúde (OMS). Esses Manuais integram os diagnósticos geralmente mais usados. O DSM e a CID podem apresentar inconsistências e deficiências; apesar disso, são amplamente utilizados e estão baseados em critérios descritivos que propiciam uma linguagem comum no âmbito da psiquiatria. As divergências, entre que doenças poderiam ser incluídas e como deveriam estar organizadas, são motivo de discussão na psiquiatria (MALDONADO et al., 2011). 
No perspectiva operacional-pragmática, as definiçôes dos transtornos mentais são formuladas de modo arbitrário, em função de sua utilidade pragmática, clínica ou para pesquisa. Neste sentido, a natureza da patologia ou do sintoma ou dos fundamentos filosóficos ou antropológicos de determinada definição não é questionada (DALGALARRONDO, 2000, p.30).

Segundo Pereira (1998 apud DUNKER, 2014, p. 100), "o projeto empíricopragmático do DSM reclama para si o qualificativo de neokrapeliniano, no sentido da delimitação precisa das entidades clínicas psiquiátricas”. O autor salienta que há diferenças significativas entre as propostas do DSM e o projeto de Kraepelin. Este considerava as entidades patológicas como se fossem doenças orgânicas. Já a perspectiva do DSM abandona a concepção de doenças mentais e a substitui por disorder (transtorno), ou seja, algo que está fora de uma ordem preestabelecida. Dunker (2014) relata que o uso do termo "transtorno" já denota uma tentativa de se distanciar da nosologia em busca de um sistema ateórico:

A superação da "confusão de línguas" seria obtida por intermédio de uma fidedignida-
de à categoria diagnóstica, ou seja, perante uma mesma configuraçáo sintomatológica;
clínicos e pesquisadores provenientes de diferentes orientaçóes teóricas e de ambientes
culturais distintos devem chegar ao mesmo diagnóstico. Para se alcançar esse objetivo,
um sistema ideal de classificação deveria fornecer critérios explícitos, operacionalmente
observáveis e que reduzissem ao mínimo o uso de interferências teóricas não diretamente
observáveis para a definição de cada quadro mental. Temos, assim, a opçáo pelo prag-
matismo como soluçáo para os impasses teóricos existentes no campo da psicopatologia
(DUNKER, 2014, p.102).

Dunker (2014) observa que o DSM não pretende ser uma psicopatologia, pois busca se constituir em um sistema de classificação fiel aos adoecimentos psíquicos. Além disso, apresenta uma racionalidade baseada em categorias confiáveis, provisórias e operacionais, ateóricas e sem impasses em relação à etiologia, o que o deixa imune a qualquer equívoco terminológico no campo da psicopatologia. $\mathrm{O}$ seu critério está fundamentado na "descrição formal do plano empírico dos fatos clínicos” (DUNKER, 2014, p. 102).

Os DSMs falam em transtornos mentais, não em doenças mentais. Isso porque o conceito de doença implica uma etiologia, uma agrupação de sintomas, um curso e um prognóstico, bem como uma certa resposta ao tratamento. Entretanto, não é possível determinar os fatores etiológicos, nem os processos patológicos subjacentes para grande parte dos quadros clínicos. Assim, a opção é descrever detalhadamente 
os critérios diagnósticos atualizados dos transtornos mentais, de modo que possa ser identificado pelos terapeutas e transmitido aos profissionais por uma linguagem comum. Neste sentido, o DSM-V, bem como as versóes anteriores do DSM, se caracteriza mais como um dicionário descritivo do que um manual de patologia (ECHEBURÚA; SALABERRIA; CRUZ-SAEZ, 2014).

A semiologia - parte da medicina que estuda os sinais e sintomas das doenças - exerce a funçấo de um dicionário que especifica o que está presente ou não no código da língua, mas que não representa um conjunto de narrativas. Assim, o diagnóstico caminha para a lógica de uma enciclopédia, cujo conteúdo indica regras de ação ou possibilidades de continuidade. $\mathrm{O}$ valor patológico dos signos poderia ser acatado pela sua força de determinação ou de indeterminação no conjunto que define um quadro. Para Dunker e Kyrillos Neto (2011, p. 3), de acordo com esse raciocínio, "o diagnóstico psiquiátrico não pode prescindir de elementos descritivos, fenomenológicos e comportamentais revelados na situação clínica na qual a relação intersubjetiva e a interpretação conservam um papel decisivo". Portanto, por um lado, se a classificação constrange em demasia o processo diagnóstico, consequentemente, prejudica a prática clínica. Porém, por outro lado, toda distinção prevê classes, categorias, oposiçóes ou conjuntos.

A ideia de que as doenças mentais dependem de construtos sociais é ameaçadora à psiquiatria por não apresentar uma estabilidade requerida para criar um sistema preditivo, ou seja, que indique uma relação de ordem entre fenômenos, pois representa o modo do que é esperado na medicina (BERRIOS, 2008). Do mesmo modo, a ideia de que as estruturas clínicas dependem do funcionamento do sistema nervoso é ameaçadora à psicanálise, por descrever o sofrimento e os sintomas em uma semiologia refratária à intervenção pela palavra (DUNKER; KYRILLOS NETO, 2011).

A psiquiatria parece buscar conectar-se com três níveis de desenvolvimento científico atual: as neurociências como principal, a genética e o resultado tecnológico desta díade, a psicofarmacologia. A questáo é que a psiquiatria não construiu elementos diagnósticos e classificatórios que fossem coerentes com estas disciplinas, cujo embasamento estaria nos mecanismos neuronais, neurotransmissores e genéticos, bem como os efeitos psicofarmacológicos no comportamento e elementos do sistema nervoso central para estabelecer uma nova nosologia com base científica (IZAGUIRRE, 2011). 
No DSM-IV está descrito que a classificação de transtornos mentais não classifica diretamente alguém como "um esquizofrênico", mas os transtornos que sofre, utilizando expressōes como "um indivíduo com esquizofrenia”. Para Esperanza (2011), é com base nesta díade - indivíduo e transtorno - que se torna possível segregar e excluir do campo o sujeito, o inconsciente e a sexualidade incorporada no sintoma. As substituiçôes estão baseadas na seguinte relação: o sintoma é substituído pelo transtorno, o corpo é substituído pelo organismo, o sujeito é substituído pelo indivíduo e o inconsciente desaparece frente ao comportamento e às condutas a serem modificadas.

$\mathrm{Na}$ ótica de Berrios (2008), as classificaçôes psiquiátricas são produtos culturais. Este autor ainda questiona se as doenças mentais são apenas epifenômenos comportamentais envolvidos ou redutíveis a alteraçóes moleculares, uma vez que uma classificação de base molecular talvez não seja de fato uma classificação de doenças mentais. Além disso, ainda salienta que o fato de a genética sozinha não explicar as patologias mentais não deveria compelir os psiquiatras à pesquisa de uma invariante social.

Apesar das inúmeras controvérsias em relação à racionalidade diagnóstica que perpetua nos DSMs, ele está em sua quinta edição e é considerado como o modelo hegemônico, no que diz respeito aos transtornos mentais. Portanto, há lugares em que o Manual é considerado conveniente.

\section{Conveniências do DSM}

O DSM é considerado conveniente em alguns aspectos, sobretudo ao favorecer o campo da medicina, o âmbito dos planos de saúde e da indústria farmacêutica, entre outros espaços.

Segundo Maldonado et al. (2011), os avanços em relação às causas subjacentes dos transtornos mentais foram mais lentos, porém, não menos importantes. As neurociências favoreceram o entendimento dos transtornos mentais sob a perspectiva biológica, com destaque ao desenvolvimento das taxonomias, consideradas como ferramentas fundamentais para identificar e classificar os transtornos psicopatológicos, os quais são utilizados no cotidiano das práticas clínicas e de pesquisa.

Para Maldonado et al. (2011), o diagnóstico é de responsabilidade prioritária dos profissionais do campo da medicina, necessitando ser preciso e específico, 
bem como válido e confiável. O recrudescimento da fidelidade dos sistemas diagnósticos em psiquiatria teve significativos avanços na descrição psicopatológica e na formulação diagnóstica integral. $\mathrm{O}$ autor considera como o fator-chave dos sistemas de classificação, que propiciou desenvolvimento de formas mais completas de comunicação, organização e informação clínica, o uso de esquemas multiaxiais. Este modelo considera alguns aspectos críticos da condição do paciente, os quais são avaliados por meio dos eixos que os descrevem dentro da sua complexidade clínica e biopsicossocial. Estes eixos são compostos por escalas categóricas e dimensionais que contribuem para o entendimento do processo saúde-doença, sendo de grande utilidade para a prática clínica da psiquiatria biológica e da psicologia cognitiva (MALDONADO et al., 2011).

Alarcón e Freeman (2015) defendem que a classificação psiquiátrica ideal deve ser composta por adequação descritiva, objetividade, operatividade, fundamento empírico, relevância sistêmica e confiabilidade. Os objetivos devem ser propiciar uma lista sucinta e clara de doenças catalogadas, com conceitos e critérios que possibilitem uma comunicação confiável; ser útil igualmente para clínicos, pesquisadores, docentes e administradores; ter ampla aceitabilidade e ser orientada por hipóteses e teorias coerentes. Os autores ressaltam que as diversidades de interpretaçôes são inevitáveis, e uma aceitação massiva pode refletir em uma medida de poder político, tanto daqueles que os adotam como por seus mentores.

A importância de fazer uma revisão nosológica - fundamentada em uma validade mais bem concebida e documentada - torna possível aos clínicos anteciparem a elaboração de qualquer diagnóstico, viabilizando um tratamento precoce, integral e mais efetivo. Além disso, uma revisão que resulta em um diagnóstico consistente servirá como guia para diversos tipos de pesquisa e protocolos padronizados que possibilitam a colaboração internacional. E que também facilitam as coberturas dos planos de saúde para atendimento médico em diversos países (ALARCÓN; FREEMAN, 2015).

Ian Hacking considera que não há possibilidades de existir um modelo médico que seja coerente para todos os sofrimentos psíquicos e defende que a pretensão do DSM de ser espelho da realidade é o grande equívoco deste Manual. Entretanto, Hacking considera que o DSM-V tem utilidade no âmbito burocrático, como base para pagamento de tratamentos e para avaliaçôes de prevalência (CAPONI, 2014). 
Frances (2016) relata que as primeiras ediçôes ( $1^{\mathrm{a}}$ e $\left.2^{\mathrm{a}}\right)$ dos DSMs eram livros desconhecidos, pouco utilizados, até que o DSM-III (1980) foi publicado e logo se tornou um best-seller, a bíblia da psiquiatria. $\mathrm{O}$ autor explica por que, a partir deste momento, os DSMs tiveram êxito:

Por ter estabelecido a fronteira crucial entre normalidade e a doença mental, o DSM ga-
nhou uma relevância social imensa, determinando uma infinidade de coisas que têm um
enorme impacto na vida da populaçáo - quem é considerado sadio e quem é doente; qual
tratamento é oferecido; quem paga por ele; quem recebe benefícios por invalidez; quem
tem direito a serviços de saúde mental, escola, colocaçáo profissional e outros; quem é
contratado para um emprego, pode adotar um filho, pilotar um avião ou ter seguro de
vida; se um assassino é um criminoso ou um paciente mental; qual deve ser a indenização
paga em uma açáo judicial; e muito, muito mais (FRANCES, 2016, p. 12).

Além desses aspectos, Frances (2016) argumenta que a inflação diagnóstica de transtornos mentais, gerada pelos DSMs, fez com que uma quantidade excessiva de pessoas passasse a tomar antidepressivos, antipsicóticos, ansiolíticos, remédios para dormir e analgésicos. Deste modo, as drogas psiquiátricas tornaram-se a maior fonte de renda das indústrias farmacêuticas. Em 2011, foram arrecadados 18 bilhôes de dólares em antipsicóticos, 11 bilhôes em antidepressivos e quase 8 bilhôes em remédios para TDAH.

As conveniências que os DSMs geram para potências como as indústrias farmacêuticas, conjuntamente com as seguradoras de saúde e a classe médica, facilitam compreender o porquê de estes Manuais tornaram-se hegemônicos na contemporaneidade. Todavia, as críticas em relação a este sistema que almeja o poder e o lucro são bastante amplas e pertinentes.

\section{Críticas ao DSM}

A ideia de que o sujeito é regido pelo cérebro e a partir dele são determinados os seus comportamentos suprime os processos de subjetivação e socialização, pois prevalece apenas o sistema biológico. Deste modo, diversos autores (citados a seguir) apresentam críticas a esse modelo, por transformar o sofrimento psíquico em patologias de cunho genético e cerebral.

Caponi (2014) faz uma análise das críticas ao DSM-V feitas por Tomas Insel, diretor do National Institute of Mental Health (NIMH), Allen Frances, chefe da equipe que elaborou o DSM-IV, e também de um texto de Ian Hacking. Lembra a autora que, um pouco antes da publicação do DSM-V, Thomas Insel anunciou 
que o NIMH não utilizaria esta proposta de classificação da APA, por se tratar de uma lista de sintomas sem consistência científica. Portanto, as pesquisas financiadas pelo NIMH não utilizariam mais este Manual como referência. Entretanto, Insel ressalta que a fragilidade científica do DSM está na falta de validade, ou seja, falta de estudos em laboratório que possam validar os diagnósticos, referentes especificamente à identificação de alteraçôes cerebrais por imagens ou detectáveis pela medição de marcadores genéticos. Caponi (2014) menciona que Insel resgata os preceitos localizacionistas e deterministas da psiquiatria biológica, iniciada na década de 1830, seguida pelos estudos de Charcot e consolidada no século XX com Kraepelin (CAPONI, 2014).

Segundo Caponi (2014, p.747), para Insel, “a psiquiatria deve concentrar seus esforços na criação de uma nova nosologia, que deverá transformar os diagnósticos pela incorporação de estudos genéticos, de imagens cerebrais e de referências às ciências cognitivas". Por este motivo, Insel considera que o DSM-5 não possa ser considerado como "padrão ouro", pois pode restringir a abertura para inserção do embasamento biológico das patologias mentais, cujas pesquisas não apresentam até o momento resultados conclusivos (CAPONI, 2014).

Allen Frances (2016) ressalta as dificuldades inerentes ao DSM-V, como diversas patologias mal formuladas, pouco claras e inconsistentes, bem como o aumento da lista de diagnósticos - a qual já era excessiva nas versóes anteriores -, novas patologias associadas à prevenção e antecipação de riscos, como a detecção de transtornos mentais em crianças. Dentre as fragilidades do DSM-V Frances ressalta que algumas como opçóes conceituais equivocadas, desacertos no processo de elaboração e redação do manual, indefiniçôes ou periodizaçôes incoerentes para alguns transtornos mentais.

Conforme Caponi (2014, p. 757), o fato de Insel e Hacking não considerarem o DSM como uma "Bíblia da psiquiatria”, e sim como um dicionário elaborado a partir de debates e consensos entre os seus autores, representa "uma crítica frágil e até impertinente", uma vez que o Manual é apresentado como uma lista descritiva dos transtornos mentais, ateórico e passível de revisôes.

Fendrik (2011) relata que, mediante as críticas ao DSM, como a relativa aos seus critérios de confiabilidade, a saída encontrada foi o argumento de que há um consenso democrático, ao passo que as siglas dos transtornos mentais são aplicáveis à maioria da população, o que as torna confiáveis. Assim, o consenso 
democrático-utilitarista é a comprovação da fundamentação científica. Além disso, há o marketing referente aos nomes de muitos especialistas em saúde mental de renome mundial, por recomendarem o uso do Manual. Na trajetória de elaboração dos DSMs, está sempre presente a promessa de que todos os possíveis erros desse manual serão sanados na próxima edição, ampliando a capacidade para detectar novos transtornos de comportamento.

Tereza Pinto (2012) relata que os profissionais que seguem a lógica dos manuais, como o DSM, acreditam na relação direta entre um distúrbio e uma droga, conduzindo para o tratamento medicamentoso. A autora cita, por exemplo, os médicos de clínica geral, responsáveis por grande parte das prescriçôes de psicotrópicos, que promovem uma disseminação da droga na sociedade.

Caponi (2014), bem como outros pesquisadores citados pela autora (ROUDINESCO, 2013; PIGNARRE, 2006), afirmam que é preciso abandonar o DSM como referência para diagnósticos psiquiátricos, pois os sofrimentos individuais estão sendo reduzidos a uma lista de sintomas imprecisos para um conjunto cada vez mais amplo de patologias mentais.

O DSM exige pelo menos cinco sinais para a classificação correta de um transtorno. Mediante esta simplicidade, Fendrik (2011) relata que muitos profissionais abandonaram o manual, voltaram a escutar a pessoa e com base na anamnese, passaram a fazer um diagnóstico mais preciso.

Para Fendrik (2011, p. 33), "um transtorno deveria ser, logicamente, algo que não se espera que ocorra, e não uma constatação feita baseada em uma 'esperança' não explicitada. Como o não esperado pode se adequar tão facilmente às mediçôes estatísticas? ". O inesperado é o contingente, ou seja, aquilo que pode ou não pode ocorrer, o imprevisto, o que irrompe e não poderia de forma alguma ser enquadrado em uma tabulação estatística, algo que representa uma contradição metodológica. Parece que definir "o esperado" com algum critério científico não é necessário, sequer nos termos do seu próprio discurso. Assim, são os comportamentos inesperados aqueles com que se estabelecem as "médias" dos desvios que continuam encorpando as páginas dos DSMs (FENDRIK, 2011).

No texto "não há classificação que não seja arbitrária e conjuntural". Bekerman (2011) afirma que a tentativa de classificação das doenças mentais realizada no DSM-IV é um fracasso por não estabelecer uma classificação que seja útil na prática clínica. Além disso, considera que o termo "transtornos mentais" é uma ficção 
hipotética, uma suposição mediante observações empíricas, pois "não há observação empírica que se possa supor pura”, o que existem são observaçôes mais suposiçôes (BEKERMAN, 2011, p.25). Para o autor, toda observação empírica pode ser apenas uma suposição e os transtornos mentais não podem ser abordados na prática clínica apenas como objetos de observações empíricas.

Segundo Fendrik (2011), um dos problemas do DSM é a falta de controle do seu uso, o que ultrapassa o domínio da APA e invade outros territórios, como as escolas, consultórios psicopedagógicos, tribunais, hospitais e serviços sociais. Isso significa que o DSM está nas mãos de profissionais de outras áreas de atuação, que agora podem denominar as pessoas com os supostos transtornos baseados em um instrumento utilizado como "referência" para tal classificação. A autora salienta que a dificuldade de estabelecer o limite entre ordem e desordem, no que diz respeito ao DSM, está progressivamente se tornando mais difícil, e a proliferação de categorias se presta a uma ridicularização, mas isto não diminui a onda expansiva. Fendrik (2011, p. 32) afirma que:

O Manual de Psiquiatria em suas últimas versôes é, nem mais nem menos, um tratado behaviorista de patologização mental da vida privada, graças ao qual quase todo comportamento "desviado" de uma normalidade intangível, estabelecida em relação ao "que se espera", tem a possibilidade de ser definida e medicada - como uma alteração da "Ordem" (disorder).

O DSM é elaborado com um caráter de dicionário enciclopédico, cujos autores são divulgados como "os melhores especialistas do mundo". Assim, os novos rótulos aos comportamentos desviados com a finalidade de conceitua-los como "transtornos mentais" globalizados são prontamente aceitos. Paralelamente ao aumento das páginas do DSM (de 132 páginas no DSM-I para 948 no DSM-V), ou seja, à ampliação do número de transtornos mentais, aumenta também a impunidade para aqueles que indiscriminadamente classificam, medem e medicalizam os comportamentos inesperados como transtornos. O Manual mostra claramente que, uma vez identificada uma desordem, não há outra possibilidade para a cura, senão o comportamentalismo e o fármaco (FENDRIK, 2011).

Segundo Esperanza (2011), a psiquiatria propõe tratar uma realidade perturbada, cujo primeiro critério, obrigatoriamente, deverá ser o da realidade de quem observa, classifica e avalia. Realidade esta que o psiquiatra se encarrega de manipular e impor a quem escape dela. Portanto, "à psiquiatrização dos atos e açôes também 
corresponde a tentativa farmacêutica de psicofarmacologizar a própria vida, o que equivale a postular que cada ato da vida de um sujeito é possível de ser medicado ou medicalizado [...]" (ESPERANZA, 2011, p. 56).

Para Caponi (2014, p. 759), o DSM funciona como "um dispositivo de segurança que reduz todos os nossos sofrimentos à lógica da intervenção biomédica, à lógica da prevenção e da detecção de riscos [...]". O Manual não delimita até onde vai o "transtorno" e onde começa a "vida real" de responsabilidade do sujeito, não há assim um limite entre o moral e o patológico, entre a ação restrita do transtorno e suas consequências, isso promove o abandono do sujeito mediante o seu sofrimento (DUNKER, 2014).

Esperanza (2011) afirma que a inconsistência teórica dos DSMs não evitou que a psiquiatria vislumbrasse nos avanços das neurociências uma oportunidade para se reivindicar cientificamente. Esta foi a alternativa encontrada para solucionar os problemas que a afetaram, principalmente a perda progressiva do valor e uso da clínica psiquiátrica, bem como o seu desalojamento no campo da medicina. Para Esperanza, a espectativa da psiquiatria do século XXI é afirmar sua pertença à medicina científica.

\section{Considerações finais}

O presente ensaio procurou mostrar como o DSM é discutido na literatura no que diz respeito à fundamentação de diagnósticos de transtornos mentais. Neste sentido, constatou-se que há controvérsias em relação ao Manual, as quais descrevemos como conveniências e críticas.

Por um lado, nota-se que há conveniências em transformar o DSM em um modelo hegemônico de compreender o sofrimento psíquico, ou melhor, o comportamento humano, pois a universalidade é considerada como um êxito deste trabalho. Há lugares em que esta lógica do DSM é conveniente, porque este modelo aproxima a psiquiatria do âmbito da medicina, facilita a burocracia dos seguros de saúde, amplia o mercado para profissionais da saúde, aumenta significativamente o número de diagnósticos de transtornos mentais e, consequentemente, o consumo de medicamentos, entre muitos outros aspectos.

Em contrapartida, há muitas críticas em relação ao DSM, pois os transtornos mentais não significam doenças, alteração que a psiquiatria fez - de doenças 
mentais para transtornos mentais - por não conseguir comprovar a etiologia de tais manifestações. O DSM apresenta as descriçōes destes transtornos, sendo que alguns poderiam ser chamados de transtornos da vida, por tratar-se de dificuldades do cotidiano. Na contemporaneidade, identifica-se certa resistência em lidar com as adversidades, e assim, áreas como a psicologia e a pedagogia, entre outras - cuja proposta é prestar atenção às pessoas no que diz respeito aos problemas cotidianos e sofrimento psíquico -, tornaram-se reféns das áreas biomédicas. Fato que se pode facilmente comprovar pelo alto consumo de medicamentos psiquiátricos pela população.

A concepção que o ser humano é comandado apenas pelo cérebro - proveniente de saberes neurocientíficos e da psiquiatria biológica - induz a pensar que é possível que o sujeito seja regido por um Manual - DSM - que o classifica em um diagnóstico e o destina à prescrição de um medicamento. Ressalta-se que esta perspectiva suprime a subjetividade da complexidade que é o ser humano, que se constitui conforme o contexto social em que está inserido e suas relações, vigorando assim um ser cerebralizado, regido pela tecnologia da medicação. ${ }^{1}$

\section{Agradecimentos}

O presente trabalho foi realizado com apoio da Coordenação de Aperfeiçoamento de Pessoal de Nível Superior -Brasil (CAPES) - Código de Financiamento 001.

\section{Referências}

ALARCÓN G, R.; D.; FREEMAN, A. M. Rutas ontológicas de la nosología psiquiátrica: ¿Cómo se llegó al DSM-5? Rev Neuropsiquiatr, Lima, v. 78, n. 1, enero 2015.

AMERICAN PSYCHIATRIC ASSOCIATION. Diagnostic and Statistical Manual of Mental Disorders, Fifth Edition (DSM-5). Arlington, VA: American Psychiatric Association, 2013.

ARAÚJO, Á. C.; LOTUFO NETO, F. A Nova Classificação Americana para os Transtornos Mentais - o DSM-5. Rev. Bras. de Ter. Comp. Cogn., v. XVI, n. 1, p. 67-82, 2014.

BEKERMAN, J. Não há classificação que não seja arbitrária e conjuntural. In: JERUSALINSKY, A.; FENDRIK, S. (Orgs.). O livro negro da psicopatologia contemporânea. São Paulo: Via Lettera, 2011, p. 23-27.

BERRIOS, G. The History of Mental Symptoms: descriptive psychopathology since the nineteenth century. Cambridge: Cambridge University Press, 1996. 
. Classificaçóes em psiquiatria: uma história conceitual. Revista de Psiquiatria Clínica, São Paulo, 35 (3), p.113-127, 2008.

. Como o passado pode nos ajudar a prever o futuro? Revista de Psiquiatria do Rio Grande do Sul, Porto Alegre, v. 29, n. 1, p. 11-12, 2007.

CAPONI, S. Loucos e degenerados: uma genealogia da psiquiatria ampliada. Rio de Janeiro: Fiocruz, 2012.

CAPONI, S. O DSM-V como dispositivo de segurança. Physis, Rio de Janeiro, v. 24, n. 3, p. 741-763, set. 2014.

DALGALARRONDO, P. Psicopatologia e semiologia dos transtornos mentais. Porto Alegre: Artes Médicas Sul, 2000.

DUNKER, C. I. L. Questôes entre a psicanálise e o DSM. J. Psicanal., São Paulo, v. 47, n. 87, dez, p. 79-107, 2014.

DUNKER, C. I. L.; KYRILLOS NETO, F. A psicopatologia no limiar entre psicanálise e a psiquiatria: estudo comparativo sobre o DSM. Vinculo, Sáo Paulo, v. 8, n. 2, p. 1-15, dez, 2011. ECHEBURÚA, E.; SALABERRIA, K.; CRUZ-SAEZ, M. Aportaciones y Limitaciones del DSM-5 desde la Psicología Clínica. Ter Psicol [online]. Santiago, v. 32, n. 1, p. 65-74, 2014.

ESPERANZA, G. Medicalizar a vida. In: JERUSALINSKY, A.; FENDRIK, S. (Orgs.). O livro negro da psicopatologia contemporânea. São Paulo: Via Lettera, 2011, p. 53-59.

FENDRIK, S. O DSM-IV: uma metafísica comportamentalista? In: JERUSALINSKY, A.; FENDRIK, S. (Orgs.). O livro negro da psicopatologia contemporânea. São Paulo: Via Lettera, 2011, p. 29-37.

FRANCES, A. Voltando ao normal. Trad. Heitor M. Corrêa. Rio de Janeiro: Graal, 2016.

IZAGUIRRE, G. Elogio ao DSM-IV. In: JERUSALINSKY, A.; FENDRIK, S. (Orgs.). O livro negro da psicopatologia contemporânea. São Paulo: Via Lettera, 2011, p. 13-22.

MALDONADO, G. G. et al . El DSM-V. Luces y sombras de un manual no publicado. Retos y expectativas para el futuro. Salud Ment. México, v. 34, n. 4, agosto, p. 367-378, 2011.

MARTINHAGO, F. Contágio social de transtornos mentais: análise das estratégias biopolíticas de medicalização da infância. 2017. Universitat Rovira i Virgili, 2017., [s. 1.], 2017. Disponível em: <http://search.ebscohost.com/login.aspx?direct=true\&db=edstdx\&AN=edstdx.10803.461 527\&lang=pt-br\&site=eds-live\&scope=site $>$. Acesso em: 4 fev. 2019.

MARTINHAGO, F.; CAPONI, S. Breve história das classificaçôes psiquiátricas. Inter. Interdisc. INTERthesis, Florianópolis, v. 16, n. 1, p. 74-91, jan-abr 2019.

ROUDINESCO, E. Por qué el psicoanálisis? Buenos Aires: Paidós, 2013. 
PIGNARRE, P. Les malheurs des psys: psychotropes et médicalisation du social. Paris: La Découverte, 2006.

PINTO, T. Crítica do empirismo aplicado à psicopatologia clínica: da esterilidade do DSM a uma saída pela psicanálise. Ágora: Estudos em Teoria Psicanalítica, v. XV, p. 405-420, dez. 2012. WHITAKER, R. Anatomía de una epidemia: medicamentos psiquiátricos y el asombroso aumento de las enfermedades mentales, Trad. J. Manuel Álvarez. Madrid: Capitán Swing, 2011.

\section{Nota}

${ }^{1}$ F. Martinhago realizou a pesquisa e trabalhou em todas as etapas da elaboração do artigo. S. Caponi orientou a pesquisa e realizou a revisão final do artigo. 


\section{Abstract}

\section{Controversies about the use of DSM for mental disroders diagnoses}

The number of diagnoses of mental disorders has grown significantly parallel to the dissemination of the editions of the Diagnostic and Statistical Manual of Mental Disorders (DSM). In this context, we developed this essay in order to understand the use of DSM as an instrument to support the diagnosis of mental disorders. To do so, we have used scientific publications by authors who have discussed DSM issues, as well as psychiatric classifications. We find that there are controversies regarding the Manual, which we describe on the one hand as conveniences, and on the other, as criticisms. There are places where this logic of the DSM is convenient, since it generates benefits to several sectors, such as health insurance and pharmaceutical industry. The main criticisms of DSM are the fact that the Manual transforms psychic suffering into cerebral pathologies.

Teywords: Diagnostic and Statistical Manual of Mental Disorders; classification; diagnosis; psychiatry. 